\title{
USING A CHANGE MANAGEMENT GAME TO IMPROVE HUMAN RESOURCES MANAGEMENT SKILLS
}

\author{
Paulino Silva ${ }^{1}$, Rui Bertuzi ${ }^{2}$, Martin Elger ${ }^{3}$ \\ ${ }^{1}$ CICE \& CECEJ - ISCAP/IPP (PORTUGAL) \\ ${ }^{2}$ CICE- ISCAP/IPP (PORTUGAL) \\ ${ }^{3}$ Cooperative State University Baden-Württemberg (GERMANY)
}

\begin{abstract}
In a very changing business environment in which mergers and acquisitions are frequent, it is fundamental for a manager to know how to deal with these happenings. It is recognized today that employees are the best asset of enterprises, and so it is fundamental to maintain them motivated especially during transforming situations. Change Management is about facts in the context of business management and administration. The focus lies on items that are not measurable and not documentable in the business world. Nevertheless, these items have a very important important impact in connection with the strategic change process of a company and their staff members. In this paper we present some lessons learned from the experience of the use of a Change Management Game at ISCAP/IPP, as a result of a partnership with Cooperative State University BadenWürttemberg, a German University. For this study, a qualitative research approach was in place, since we used qualitative methods, mainly observation and semi-structured interviews. ISCAP/IPP is a business school of higher education that provides diverse programmes of studies in business areas: accounting and management, marketing, international commerce, business communication, secretary management, etc. Nevertheless, students miss some skills related with the human resources management, which can be improved through this learning experience. There are some important issues that participants need to consider in a company change process, namely national and regional differences, company specific differences, staff functions, visible things (such as room design), not visible things (such as strategy), invisible barriers of the employees towards the change and the new, published and public opinion about the company and its staff, hidden agendas, and outside presentations. The participant team, which has the function of Change Managers guides and instructs the organisation through the different phases of the change process. The Change Management Game includes 5 phases of change: 1) Attention; 2) Motivation; 3) Qualification 4) Commitment; and 5) Internalization. In each phase participants use interventions in order to improve the level of commitment of employees. The interventions of each phase have a higher ranking focus than the individuals which have to take part. Thus before each phase of the game the team has to discuss which interventions will be applied. Afterwards the individuals who fit to the planned interventions and/or who have to take part are put in them. It is the aim of the participants to bring almost all types of human personality within the organisation to personal action in the change project. Participants need to be deeply engaged to participate as active and effective persons to perform adequately the new tasks. At ISCAP-IPP we used the Change Management Game having a multicultural and interdisciplinary background for several editions, having the participation of students from different areas of studies and from several countries, including Portugal, Germany, Romania, Lithuania, France, just to mention a few. Feedback from students so far, was very positive, as they consider to participate again in a similar experience if they have the opportunity.
\end{abstract}

Keywords: Change Management Game, Human Resources Management, Motivation; Commitment.

\section{INTRODUCTION}

Today we live in a very complex world. Companies are coming and going, successful business in the past need to be changed completely for the new reality. Lots of changes are in place and the rhythm is very fast. Nevertheless, organizational change is very hard, because in order to make a successful transformation, we must change more than just the structure and operations of an organization, we need to change people's behaviour [1].

Mergers and acquisitions, for example, are very common facts nowadays, and all staff have to deal with that, even in very stressful situations. We, as human beings need to be aware of all these changes and, professionally adapt ourselves to perform well our functions. 